\title{
"Latin American News Agency Should be Formed..." Las agencias de noticias internacionales en el México posrevolucionario, 1920-1934
}

\author{
SEBASTIÁN RIVERA Mir \\ Departamento de Ciencias Sociales \\ Universidad Autónoma Metropolitana-Unidad Cuajimalpa \\ sebastianriveramir@gmail.com
}

\begin{abstract}
Resumen
En el presente artículo se analizan las agencias de información internacionales vinculadas a los gobiernos posrevolucionarios, entre 1920 y 1934. Este tema no ha sido previamente abordado ni por la historiografía mexicana, ni por los estudios comunicacionales. El objetivo es penetrar en el complejo escenario informativo que se comenzó a construir durante este periodo. Las agencias fueron diseñadas en un contexto donde Estados Unidos realizaba una fuerte campaña propagandística en contra de la revolución mexicana, y los gobiernos de México decidieron contrarrestar esta situación a través de una serie de iniciativas donde las agencias ocuparon un espacio importante. En este escenario se recurrió metodológicamente a la idea de construcción de frentes contrahegemónicos desarrollada por Jorge González. A lo largo de la investigación se distinguieron más de una decena de este tipo de entidades, y se lograron establecer los mecanismos que utilizó el Estado mexicano para desplegar sus objetivos.
\end{abstract}

Palabras clave: agencias de información; propaganda; corresponsales; gobiernos posrevolucionarios; periodismo.

\section{"A Latin American News Agency Should be Formed..." International News Agency in Post-revolution Mexico, 1920-1934}

\begin{abstract}
This article analyzes the international information agencies linked to post-revolutionary governments, between 1920 and 1934. This topic has not previously been studied either by Mexican historiography or communication sciences. It aims to understand the complex news scenario that began to take shape during this period. The agencies were established while the United States was pursuing an intense propaganda campaign against the Mexican Revolution, and the governments of Mexico decided to counter this situation through a series of initiatives in which the agencies occupied an important space. In this context, the methodological decision was taken to use Jorge González's idea of constructing counterhegemonic sources. The research identified over ten of this type of entities, and identified the mechanisms used by the Mexican State to achieve its objectives.
\end{abstract}

Key words: information agencies; propaganda; correspondents; post-revolutionary governments; journalism. 


\title{
"Latin American News Agency Should be Formed..." Las agencias de noticias internacionales en el México posrevolucionario, 1920-1934
}

\author{
Sebastián Rivera Mir
}

$\mathrm{E}$ n el presente artículo se intentará complejizar nuestro conocimiento sobre los flujos informativos en el México posrevolucionario. El objetivo es arrojar algunas luces sobre la intrincada relación que se dio entre la información internacional y los propósitos políticos de los gobernantes mexicanos. En este periodo, mientras Estados Unidos se erigía como el principal transmisor de noticias a escala mundial, México luchaba por desprenderse de la propaganda estadunidense que lo catalogaba como un país bárbaro e incivilizado. El problema radicaba precisamente en la fortaleza de su vecino y en la contrastante debilidad comunicacional mexicana. Por este motivo las autoridades del país debieron recurrir a toda su creatividad para posicionar sus propuestas en el plano internacional. Embajadores, cónsules, artistas, pintores, escritores, periodistas, músicos, actores, entre otros, se vieron inmersos en una campaña propagandística que buscaba limitar el desequilibrio informativo. Esto se concretó en giras, en intercambios editoriales y académicos, en la entrega de becas, en la construcción de bibliotecas y en muchas otras actividades (Yankelevich, 1997). El trabajo que a continuación se expondrá aborda una de estas facetas: la construc- ción de un escenario informativo favorable a escala internacional. ${ }^{1}$

No se trata de hacer listas con los contenidos extranjeros que se divulgaron en tal o cual medio, como muchos trabajos acostumbran (Morales, 2001). La tarea propuesta apunta a analizar las estructuras mediante las cuales este tipo de información logró circular. En este sentido, entiendo que los medios de comunicación no son sólo correas transportadoras de los discursos ideológicos; al contrario, inciden de manera directa en la propia configuración de los mensajes. No podemos concentrarnos en el análisis de los discursos propagandísticos y olvidar los mecanismos que ayudaron a movilizar dichas propuestas (Martín-Barbero, 2010). La perspectiva planteada se entronca teóricamente con la postura de Jorge González relacionada con los frentes culturales. A su juicio, el enfrentamiento por la hegemonía, en un sentido amplio del concepto, se basa en la disputa simbólica en determinadas zonas compartidas o "arenas” (González, 2001, pp. 9-45). Fue precisamente esto

${ }^{1}$ El énfasis está puesto en las estrategias del gobierno mexicano, pero no podemos perder de vista la enorme maquinaria que desplegaron las autoridades estadunidenses. Véase especialmente Serna (2010).

\section{()(1) (}


lo que intentaron los gobiernos mexicanos al cuestionar el dominio estadunidense sobre el tráfico de información.

En términos concretos, este artículo se propone desentrelazar la telaraña que se construyó en torno a la circulación de noticias extranjeras durante el periodo. Diarios, revistas, libros, corresponsales, periodistas, activistas, espías, agencias noticiosas, radios, cines, entidades gubernamentales, telégrafos, correos, se entrecruzaron para construir un enmarañado escenario informativo. La complejidad de este proceso ha sido escasamente abordada y los estudios históricos se han detenido en medios específicos o sólo en la vinculación del Estado con las empresas periodísticas (véase, por ejemplo, Burkholder, 2007; González, 2006). Pero, como sucede actualmente, una de las palabras clave para pensar en los medios es convergencia. Me parece necesario que los análisis retomen los elementos que permitieron la vinculación entre los distintos espacios informativos.

Para acotar mi exposición, el énfasis estará puesto, por un lado, en la relación del gobierno mexicano con las agencias informativas en el particular contexto posrevolucionario, y en una segunda parte, en tres entidades específicas: las agencias Ariel, Trens y Duems. Analizar los flujos mediáticos requiere observar con detenimiento tanto la estructura de los propios medios y sus vínculos con el Estado, como el desempeño de los distintos actores en este escenario. Esto debe permitirnos comprender las tensiones que envuelve la práctica comunicativa, cuyos límites se encuentran atravesados por lógicas de dominación, de negociación, de consumo cultural, de alternativas a la hegemonía, de rutinas laborales, de prejuicios latentes, entre otros problemas (Chomsky y Herman, 2003). De hecho, no hay que olvidar que las agencias y los corresponsales desempeñan múltiples papeles al momento de ingresar información desde el exterior, y a la vez publicar en el extranjero las noticias que obtienen en México. Las prácticas comunicativas siempre tienen más de una faceta.

Finalmente, el artículo intenta discutir una noción demasiado aceptada, tanto en la historiografía mexicana, como en los estudios comunicacionales latinoamericanos. Me refiero particularmente a la idea de que las informaciones internacionales han sido monopolizadas imperialmente por las grandes agencias creadas en el siglo XIX, ${ }^{2}$ y que los países latinoamericanos sólo recién en la década de 1960 comenzaron a construir alternativas contrahegemónicas (véase Díaz, 1991). Esta propuesta, que en su momento movilizó a los periodistas del continente en pos de la independencia mediática, también limitó nuestra comprensión histórica de la capacidad creativa que tuvieron los "informadores” de América Latina en los años previos.

En primer lugar hagamos una rápida revisión de las condiciones que los periodistas y las agencias internacionales enfrentaron en el México posrevolucionario.

\section{UN ESCENARIO EN DISPUTA}

Si consideramos la división del mundo que realizaron las cuatro principales agencias informativas en 1876, México fue

${ }^{2}$ Véase, por ejemplo, la "historia oficial" de Reuters en Read (1999). Una visión crítica en Desbordes (2008, p. 121-139); Putnis (2006). 
catalogado como zona neutral (Rantanen, 2006, pp. 19-35). ${ }^{3}$ Esto significaba que todas ellas podían desplegar sus servicios en el país, a diferencia de otros lugares donde se estableció un monopolio. Sin embargo, después del colapso de la Gran Guerra, las oficinas estadunidenses comenzaron a ganar espacio sistemáticamente. ${ }^{4}$ De ese modo, si observamos los diarios nacionales entre 1920 y 1934 podemos ver que la mayoría de las noticias provenían de los grandes consorcios del vecino del norte, Associated Press (AP) y United Press (UP).

En ese contexto, la evaluación que hizo el gobierno mexicano fue la siguiente:

En los periódicos extranjeros, [hay] más información acerca de los disturbios y fricciones, luchas y escándalos en México, que lo que se publica acerca de educación, irrigación, agricultura, recursos naturales y, lo que es información realmente constructiva. ${ }^{5}$

Esta visión incluso fue defendida en instancias supranacionales, como el Primer Congreso Panamericano de Periodistas, realizado en Washington en 1926. En esa ocasión la principal crítica fue la deficiencia y la escasez de noticias sobre América Latina en Estados Unidos, además “United State news agencies do not cover

\footnotetext{
${ }^{3}$ Una visión más amplia en Mattelart (1998). También Álvarez (2005).

${ }^{4}$ Después de 1917, el cártel de las agencias de comunicación estuvo compuesto por Reuters, Havas, AP y UP. La agencia alemana Wolf fue relegada a un segundo plano. Véase Cuthbert (1980).

${ }^{5}$ Corresponsales de periódicos, 1927 (sin fecha exacta). Dirección General de Investigaciones Políticas y Sociales. Caja 24, exp. 32, f. 3. Archivo General de la Nación (AGN), México.
}

the area adequately and hence a Latin American news agency should be formed" (Gardner, 1967, p. 4). ${ }^{6}$ No cubrir el área adecuadamente eran palabras de cortesía para evitar acusar directamente a los medios estadunidenses de llevar a cabo una campaña en contra del gobierno de Plutarco Elías Calles. ${ }^{7}$ Aunque en otras instancias esta aseveración fue realizada sin el menor problema.

La imposibilidad de controlar las comunicaciones llegaba a tal grado que el gobierno aseguraba que "la Compañía Telegráfica Mexicana 'Western Union' está sirviendo de medio de comunicación entre los enemigos de nuestro gobierno y los elementos extranjeros radicados en el País". 8 A esto se sumaban las cuantiosas deudas que Telégrafos Nacionales había contraído con esta empresa estadunidense. Así, la hegemonía cultural se entrelazaba con la dependencia económica.

${ }^{6}$ Contra la postura de que la Inter American Press Association habría logrado la libertad de prensa en el continente, véase Díaz (1991).

${ }^{7}$ Este tipo de evaluaciones no detuvieron a las autoridades mexicanas a la hora de intentar granjearse las simpatías de las agencias estadunidenses, incluso en 1924 entregaron franquicias telegráficas a AP y le permitieron transmitir a través de la estación inalámbrica de Chapultepec. El corresponsal de AP, F. C. Scoville, le escribió a Álvaro Obregón agradeciéndole. A su juicio "se efectuó un cambio marcado en la prensa de los Estados Unidos y otras naciones que, hasta entonces, y debido a la congestión del telégrafo en esta capital y a la activa propaganda rebelde, llenaban columna tras columna con noticias falsas y desfavorables". Carta de F. C. Scoville a Álvaro Obregón, 7 de marzo de 1924. Fondo Presidentes Obregón-Calles. Exp. 721-P-18, f. 1. AGN, México.

${ }^{8}$ Censura telegráfica, 17 de enero de 1927. Dirección General de Investigaciones Políticas y Sociales. Caja 16, exp. 30, f. 1. AGN, México. 
Esta situación significó en la práctica que los mandatarios posrevolucionarios destinaran especiales esfuerzos a sus estrategias comunicacionales. El principal actor de este proceso fue el poder ejecutivo, aunque en ningún caso el único presente. El presidente, los secretarios de Estado, los diplomáticos y toda una gama de funcionarios menores, destinaron recursos y tiempo a las actividades propagandísticas. De ese modo, México dio un impulso importante a todo lo que significara difundir, publicar, editar. Una parte de este esfuerzo podemos verla reflejada en las páginas de El Libro y El Pueblo, que editó la Secretaría de Educación Pública (SEP) y que reseñó las iniciativas que se desarrollaron en esta materia. La revolución mexicana se transformó así en un faro que irradiaba hacia el sur del continente, pero también hacia el vecino del norte. ${ }^{?}$

En esta lógica, el nodo informativo que representó México atrajo no sólo a quienes buscaban conocer la realidad local, sino a un amplio espectro de "publicistas" que pretendieron utilizar al país como centro de emisión noticiosa. En este aspecto, uno de los casos más extraños fue la llegada de periodistas haitianos en 1929. Sus intenciones eran realizar desde la ciudad de México una campaña de prensa capaz de conmover al mundo respecto a la situación dictatorial que atravesaba su país. Sin detenerse por las barreras que involucraba la diferencia idiomática, Joseph Jolibois Fils, director de Le Courrier

\footnotetext{
${ }^{9}$ Siguiendo con el ejemplo de El Libro y El Pueblo, podemos ver que si bien estaba orientado por un sentimiento latinoamericanista, el lugar donde se distribuyó con más abundancia fue precisamente Estados Unidos. Véase por ejemplo, El Libro y El Pueblo, año III, t. III, núms. 1-2 y 3, enero a marzo de 1924.
}

Haitien y Pierre Moravia Morpeau, enfrentaron sin descanso sus actividades propagandísticas y lograron que sus publicaciones aparecieran en medios desde Buenos Aires hasta Nueva York. ${ }^{10}$

Evidentemente no todos estos intentos fueron exitosos, pero a grandes rasgos, durante la década de 1920 la ciudad de México fue un lugar privilegiado para emprender este tipo de iniciativas. Desde prácticamente 1921, México contaba con comunicación fluida con Chile y Argentina, los países más alejados del continente, gracias a la instalación de sistemas de radiotransmisión. En esas mismas fechas, el gobierno de Álvaro Obregón, a través de la Secretaría de Relaciones Exteriores (SRE), había entregado a los países centroamericanos los equipos necesarios para la transmisión inalámbrica. ${ }^{11}$ El objetivo final de las autoridades mexicanas era crear una red cablegráfica que permitiera enviar y recibir noticias, sin que los cables pasaran antes por Nueva York. "En consecuencia -informaba El UniversalMéxico será el paso obligado de todos los aerogramas de los países surianos a Europa y Norte América."12

${ }^{10}$ Véase, Correspondencia de Rafael Heliodoro Valle con Jolibois Fils. Fondo Rafael Heliodoro Valle. Exp. 1093, doc. 5. Fondo Reservado UNAM (FRUNAM), México.

${ }^{11}$ Memorándum. 23 de junio de 1922. Fondo Legación de México en Buenos Aires. Leg. 20, exp. 1, f. 47. Archivo Histórico de la Secretaría de Relaciones Exteriores (AHSRE), México. Esto provocó malestar entre las autoridades estadunidenses.

${ }^{12}$ Centro de comunicaciones de la América Central. El Universal, 2 de agosto de 1926, México, p. 1. Por supuesto, esta evaluación optimista debe matizarse, pues para muchos Inglaterra quedaba más cerca de todos los puntos de América Latina que los países latinoamericanos entre sí. Una carta demoraba 
La preocupación gubernamental por las comunicaciones también impulsó los planes de alojar varias reuniones internacionales de periodistas, como la realizada en Mérida, Yucatán en $1923^{13}$ o el Congreso Mundial de la Prensa que sesionó en la ciudad de México en 1931. Cuando este evento fue inaugurado, el 10 de agosto, la Agencia Trens difundió internacionalmente las declaraciones de Juan de Dios Bojórquez, en aquel momento director de El Nacional. A su juicio:

We hope its labors will be attended by complete success and that, as a Mexican victory, it will result in foreign journalists doing justice our nation, after having had contact with us. We do not ask for exaggerated praise or propaganda, but only that a little goodwill be brought into play in the judging of this fighting people, lover of liberty and vilified by all news gathering agencies through out and especially by AngloAmerican agencies. ${ }^{14}$

menos en llegar de Buenos Aires a Londres, y después de Londres a la ciudad de México, que si se mandaba directamente de Argentina a México. Véase Carta de Víctor Raúl Haya de la Torre a Esteban Pavletich, Oxford, 15 de noviembre de 1926, reproducida en Planas (1986).

${ }^{13}$ Este congreso fue impulsado por la Prensa Asociada de los Estados de México, que de alguna manera retomaba el modelo organizativo de la Associated Press, menos jerarquizado que las otras agencias internacionales. Y aunque el gobierno no participó oficialmente, sí financió viajes, ayudó a los organizadores y utilizó sus legaciones en Centroamérica para asegurar su éxito. Véase Congreso de Periodistas en Mérida, Yucatán, 1923. Leg. 7-16-45. AHSRE, México.

${ }^{14}$ Mexico City Press Comments on World Press Congress. Mexican Daily Press, agosto de 1931, p. 1, México.
Evidentemente México buscaba posicionarse como uno de los centros informativos del continente. Pero no todas las condiciones que ofrecía el país fueron favorables para la generación de un espacio informativo internacional.

\section{LAS CONTRADICCIONES LOCALES}

En primer lugar el espacio que los medios de comunicación destinaban a las noticias internacionales siempre fue pequeño en comparación con otros tipos de información. Cierto nacionalismo se apoderó de las páginas de los periódicos y de sus redacciones. En el diario Excélsior, el 10 de diciembre de 1922 apareció una nota, sin firmar, donde se rechazaba la presencia de extranjeros en los periódicos de México. Este diario decía:

haciendo a un lado resquemores, editoriales acerca de la plaga de guatemaltecos, haitianos, nicaragüenses, etc., etc., que ha caído sobre nuestro país... Bien está que busquemos la cultura en Francia, en Italia, pero ¿en el Caribe o en Centroamérica? ¿Qué nos pueden aportar esos países? Esperemos que el señor Pani remediara [sic] el abuso que está cometiendo (el de que individuos procedentes de otros países de raza hispanoamericana militen en la prensa política de México) y que preferirá los mexicanos a los filibusteros, como lo demanda la Constitución y lo exige el patriotismo (citado por Díaz, 2008, p. 126). ${ }^{15}$

${ }^{15}$ Esta nota se reprodujo en El Imparcial, 11 de diciembre de 1922, p. 3, Guatemala. Véase también, Memorándum relativo a las actividades periodísticas de algunos hondureños residentes en la ciudad de 
Este tipo de rechazo laboral xenófobo fue creciendo con el paso del tiempo y el aumento de los problemas económicos de cada periódico. También hay que considerar que el pago que recibían los periodistas de los medios masivos en muchas ocasiones no alcanzaba para cubrir sus gastos mensuales. De ese modo, era normal que los reporteros además de redactar o editar las páginas de algún diario, desarrollaran otras actividades, ya fuera en otros medios, o en espacios académicos o burocráticos. ${ }^{16}$ En ese contexto cualquier tipo de tensión rápidamente se transformaba en un problema.

Si observamos los grandes medios de difusión veremos que muchos de ellos tuvieron graves problemas de financiamiento, pese a recibir dineros por el avisaje, la venta directa en las calles y además apoyos gubernamentales (Torres, 1937; Velasco, 1955). Incluso los periódicos más grandes se vieron afectados por quiebras e intervenciones financieras del Estado (Burkholder, 2007). Pero si ampliamos el campo de estudio a aquellas publicaciones o revistas de tiraje limitado, carentes de financiamiento a mediano plazo, con fines políticos o culturales específicos, la situación se vuelve aún más crítica. Por ejemplo, el periódico del Partido Comunista Mexicano (PCM) El Machete, cuya continuidad incluso clandestina fue encomiable, nunca tuvo estabilidad económica. De hecho, en 1925

México, 20 de febrero de 1935. Leg. III-307-18. AHSRE, México.

${ }^{16}$ Véanse, por ejemplo, muchas de las cartas de Rafael Heliodoro Valle, donde se verifican las dificultades que enfrentaban los periodistas, incluso aquellos reconocidos como Valle. Fondo Rafael Heliodoro Valle. FrunAm, México. cuando un agente confidencial de Gobernación visitó sus oficinas en busca de información sobre sus fuentes de financiamiento, el administrador del periódico, desconociendo las intenciones del funcionario, lo invitó a publicar en el órgano obrero. A cambio, el funcionario policial debía darles algún material que les permitiera ampliar el tiraje. ${ }^{17}$ No sabemos si finalmente el texto del agente se publicó, pero este caso nos grafica el contexto donde se desarrollaba la prensa del periodo. Alrededor de los medios de la izquierda mexicana se construyó una mitología sobre el oro bolchevique, pero el agente, desechando esta idea ficticia, estaba especialmente interesado en las contribuciones de los políticos mexicanos, senadores o gobernadores. En aquel entonces llegó a establecer que solamente el gobierno de Jalisco lo distribuía entre los obreros y campesinos de la región. Sin embargo, esta ayuda no era suficiente para que El Machete superara su precaria existencia.

Otros medios de este tipo, como Verbo Rojo, de filiación anarquista, establecían que la única forma de recibir dinero era a través de las donaciones de los propios obreros y simpatizantes. Rechazaban cualquier aporte de sectores burgueses o del Estado. Sin embargo, también culpaban a los mismos trabajadores por su condición: "no quieren saber nada ni les importa vivir miserablemente, tal es el grado de degeneración causada por la moral

${ }^{17}$ El Machete. Clausura de su imprenta, 1929. Fondo Dirección General de Investigaciones Políticas y Sociales. Caja 34, exp. 3. AGN, México. Este tipo de donaciones era clave pues la Secretaría de Gobernación tenía cierto control sobre la distribución de papel para las imprentas. 
burguesa" ${ }^{18}$ De todas maneras, recibían directamente apoyo de sus camaradas en Estados Unidos, al igual que noticias y artículos. Estos nexos permitían que los periódicos circularan entre los mexicanos residentes en el vecino del norte.

Desde otra perspectiva, las imprentas pasaban de una mano a otra sin importar las condiciones políticas de estos traspasos. ${ }^{19} \mathrm{La}$ imprenta La Lucha, que funcionaba en la 2da. calle de los Héroes, se adscribió por algunos años a un grupo obrero asociado a la CROM, hasta que su dueño se escindió de dicho organismo y decidió venderla a unos sacerdotes. Una vez que se le cambió el nombre, la Imprenta Teresita se dedicó en 1929 a imprimir una buena parte de la propaganda clerical que circulaba en la ciudad de México. Por este motivo, los agentes del Departamento Confidencial de Gobernación la tuvieron muy vigilada. De hecho, "por el examen de los lingotes y tipo de los linotipos se advierte que difícilmente puede haber en la ciudad iguales". ${ }^{20}$ De ese modo, mientras la prensa católica se libraba de las carencias financieras debía sufrir un control exhaustivo por parte de las autoridades.

Algunos impresores sufrieron la violencia del Estado, no sólo mediante el

${ }^{18}$ Verbo Rojo. Periódico anarquista, 16 de octubre de 1929. Fondo Dirección General de Investigaciones Políticas y Sociales. Caja 34, exp. 6, f. 2. AGN, México.

${ }^{19}$ Imprenta Teresita. Investigar si se hace propaganda religiosa y sediciosa. 31 de mayo de 1929. Fondo Dirección General de Investigaciones Políticas y Sociales. Caja 34, exp. 2. AGN, México.

${ }^{20}$ Imprenta Teresita. Investigar si se hace propaganda religiosa y sediciosa. 31 de mayo de 1929. Fondo Dirección General de Investigaciones Políticas y Sociales. Caja 34, exp. 2, f. 1. AGN, México. saqueo y la destrucción de sus maquinarias, sino en carne propia. Otro agente del Departamento, sin identificar, participó en 1929 en las pesquisas sobre los talleres linotipográficos La Mercantil, propiedad de Luis Álvarez, hermano del general José Álvarez, en aquel entonces jefe del Estado Mayor Presidencial. Para ubicar la dirección exacta de la imprenta fue necesario que los funcionarios policiales hicieran prisionero a Genovevo Alatorre, a quien se le "dio tormento con objeto de que, como papelero que es, declarara de dónde procedía esa hoja". ${ }^{21}$ Una vez allanados los talleres, los funcionarios sólo encontraron un folleto titulado La voz de María.

En el plano de las comunicaciones telegráficas, la postura de algunas autoridades fue que

salvo mejor parecer de usted, de que se censuren los mensajes que se trasmitan por esa oficina, procedentes del extranjero, comunicando este acuerdo a la Secretaría de Comunicaciones, a efecto de que se comisionen empleados competentes y discretos para que desempeñen este servicio. ${ }^{22}$

Esto fue escrito por Francisco M. Delgado, jefe del Departamento Confidencial, al secretario de Gobernación en 1927. Sin embargo, a finales de ese mismo año, el presidente Plutarco Elías Calles decretó que se debía levantar toda censura telegráfica. Pese a ello la Secretaría de Guerra

${ }^{21}$ Luis Álvarez. Clausura de sus talleres linotipográficos La Mercantil. 2 de abril de 1927. Fondo Dirección General de Investigaciones Políticas y Sociales. Caja 34, exp. 16, f. 1. AGN, México.

${ }^{22}$ Censura telegráfica. 17 de enero de 1927. Fondo Dirección General de Investigaciones Políticas y Sociales. Caja 16, exp. 30, f. 1. AGN, México. 
mantuvo la censura incólume. ${ }^{23}$ Estas tensiones al interior del gobierno deben comprenderse como parte de un proceso de negociación respecto a qué hacer con los diversos problemas que enfrentaba y nos permite deconstruir la idea de un Estado monolítico y unívoco.

El mismo esquema de censura que se aplicaba a los telégrafos operaba en la oficina de correos, donde los encargados debían enviar a Gobernación una copia de toda la correspondencia que parecía sospechosa. ${ }^{24}$ La censura alcanzaba especialmente a los periódicos que se producían en el extranjero y se repartían a través del correo. Tierra y Marine Workers Voice de Nueva York; La Organización Obrera y Bandera Negra de Buenos Aires; Acción de Necochea, Argentina; Federación de España; El Trabajador Latinoamericano de Montevideo; La Verite de París, entre otros, fueron periódicos cuya circulación fue prohibida. ${ }^{25}$

Los consulados y las embajadas en el extranjero desempeñaban una función cen-

${ }^{23}$ Censura telegráfica. 10 de mayo de 1929. Fondo Dirección General de Investigaciones Políticas y Sociales. caja 16, exp. 30, f. 4. AGN, México.

${ }^{24}$ Según la entidad de Gobernación, esto funcionó bien hasta que se cambió el esquema y la información fue entregada directamente a la Comisión de Seguridad de la Inspección General de Policía. Oficina local de Correos. 1 de abril de 1927. Fondo Dirección General de Investigaciones Políticas y Sociales. Caja 16, exp. 31, f. 21. AGN, México.

${ }^{25}$ Periódico que se edita en Nueva York y que no debería circular en nuestro país, 1930. Fondo Dirección General de Investigaciones Políticas y Sociales. Caja 34, exp. 15. AGN México; Folleto que se prohíbe su circulación en el país. 1930, Fondo Dirección General de Investigaciones Políticas y Sociales. Caja 34, exp. 17. AGN, México; Periódico que se prohíbe su circulación en el país. 1930. Fondo Dirección General de Investigaciones Políticas y Sociales. Caja tral en el control de la información que salía de México. Mientras auscultaban la prensa en sus respectivas localidades, cada una de las legaciones enviaba informes sobre las labores inconvenientes para el país. De ese modo, cuando algún periodista publicaba noticias que cuestionaban el devenir político mexicano, inmediatamente se ponían en marcha los mecanismos para contrarrestar este tipo de acciones. ${ }^{26}$ En este aspecto las autoridades tuvieron una especial atención con aquellos informadores que habían visitado México o quienes previamente habían recibido el apoyo por parte del gobierno. Por ejemplo, el nicaragüense Hernán Robleto, quien había sido ayudado en su labor publicitaria por Plutarco Elías Calles en el contexto del conflicto entre Nicaragua y Estados Unidos, fue duramente criticado por publicar en Francia un texto en contra de la revolución mexicana (Robleto, 1931). La legación en París rechazaba su "espíritu de desdeñosa superioridad”. 27

34, exp. 18. AGN, México; Periódicos y folletos que se prohíbe la introducción en el país. 1930. Fondo Dirección General de Investigaciones Políticas y Sociales. Caja 34, exp. 19. AGN, México.

${ }^{26}$ Por ejemplo, la embajada de México en Brasil contrató los servicios de la Agencia Americana para contrarrestar los efectos de las noticias perjudiciales que distribuían AP, UP y Havas en la zona. Aunque en 1926 el embajador, Pascual Ortiz Rubio, catalogaba esta situación como inútil, porque cuando había un tema importante las estructuras administrativas de la Secretaría de Relaciones Exteriores impedían que la información fluyera con la misma rapidez que tenían las agencias comerciales. Contrato con la Agencia Americana. 28 de diciembre de 1926. Leg. 18-5-90, fs. 1-3. AHSRE, México.

${ }^{27}$ L'Amerique Latine. Artículo publicado en dicho periódico que fue escrito por Hernán Robleto. 10 de 


\section{LAS AGENCIAS}

En este contexto, que tenía su parte positiva y también su lado oscuro, las agencias de información internacional proliferaron. Veamos unos ejemplos para comprender cómo se desarrollaron estas entidades en la ciudad de México.

El primer intento de fundar una agencia de informaciones extranjeras durante el periodo, que he podido documentar, se refiere al proyecto de Manuel Múzquiz Blanco, José Luis Velasco y J. A. Velasco en octubre de $1920 .{ }^{28}$ Aunque su justificación no se refería directamente a la propaganda a favor de la "revolución", sí estableció que dicho proceso había puesto al país en el centro del interés mundial -exponían-, "Hasta el presente toda la información mexicana, está en manos de agencias extranjeras y de corresponsales particulares, para los cuales México es sólo un campo de operaciones mercantiles”. ${ }^{29}$ La Agencia de Información Mexicana proponía vincular lo nacional con lo extranjero, dando un especial énfasis a la familia latinoamericana. Por este motivo, sus impulsores pedían al presidente Adolfo de la Huerta que les otorgara una franquicia cablegráfica, y que las distintas secretarías les dieran las informaciones que consideraran pertinentes. Finalmente el ejecutivo decidió darles una franquicia telegráfica de 2000 palabras

noviembre de 1932. Fondo Dirección General de Investigaciones Políticas y Sociales. Caja 34, exp. 24, f. 1. AGN, México.

28 Sobre la actividad periodística de este grupo, véase Múzquiz (1925).

29 Propuesta de agencia de información mexicana. 27 de octubre de 1920. Fondo Presidentes Obregón-Calles. Exp. 711-a-28, f. 2. AGN, México. diarias. ${ }^{30}$ Este tipo de exenciones se transformó en el principal mecanismo de apoyo a la circulación de noticias internacionales, aunque al mismo tiempo fue una herramienta de control por parte del gobierno.

La Agencia Informativa Prensa Nacional y Extranjera funcionó durante el año 1924 en la 5ta. de Nuevo México, en el centro del Distrito Federal. Su gerente fue David Camacho Silva y estuvo sometida a la vigilancia de las autoridades mexicanas. Por este motivo, cuando el gobernador de Nayarit, Pascual Villanueva, preguntó a la Secretaría de Gobernación si tomaría su servicio de noticias, algo que ya habían realizado muchos gobernadores, el agente núm. 2 del Departamento Confidencial fue enviado a investigar qué hacía dicha agencia. ${ }^{31} \mathrm{Su}$ informe empieza describiendo sus instalaciones: era una pequeña tiendecilla que estaba justo frente a Excélsior. Para profundizar sus conocimientos el funcionario se presentó ante su dueño como vendedor viajero, se ganó la confianza de Camacho Silva y este lo transformó en su representante, "así como la de un Sr. alemán cuñado suyo, maestro en fotografía y amplificador de retratos". ${ }^{32}$ El investigador describe las lógicas de funcionamiento de la agencia de la siguiente manera:

${ }^{30}$ Carta de José Luis Velasco al presidente de la república. 27 de septiembre de 1923. Fondo Presidentes Obregón-Calles. Exp. 242-T1-L. AGN, México.

${ }^{31}$ Agencia informativa prensa nacional y extranjera. Averiguar su seriedad. 1934. Fondo Dirección General de Investigaciones Políticas y Sociales. Caja 6, exp. 7. AGN, México.

32 Agencia informativa prensa nacional y extranjera. Averiguar su seriedad. 20 de noviembre de 1924. Fondo Dirección General de Investigaciones Políticas y Sociales. Caja 6, exp. 7, f. 4. AGN, México. 
consiste en mandar noticias telegráficas, recortes de periódicos, e informaciones por correo, a los periódicos de los estados, a particulares, gobernantes, negociaciones, y en general a todo el que quiera ser su cliente. ${ }^{33}$

El funcionario quedó de sacarse una fotografía, que le tomaría el "alemancito", la cual a su vez le serviría como tarjeta de presentación. Le entregarían además una credencial de representante e instrucciones por escrito para establecer agencias en todas las poblaciones que juzgara conveniente. La "tiendecilla" había comenzado a funcionar en 1882, impulsada por el padre de Camacho, aunque en aquel entonces se dedicaba a los encargos. "Y sería muchísimo más si a consecuencia de la revolución fracasa$\mathrm{da}$, el Sr. Silva no hubiese tenido que salir de México, abandonando su negocio". ${ }^{34}$ Estas palabras de inmediato llamaron la atención del funcionario de Gobernación.

Al día siguiente, el agente se presentó otra vez en la 5ta. de Nuevo México. En medio de la conversación, que empezaba a ponerse amenazante, porque lo podían descubrir, comentó al dueño su "gran pena porque la ambición de los jefes militares hubiese hecho fracasar la pasada rebelión cuyo triunfo pedían todos los hombres honrados, y pude advertir el buen efecto que le hicieron mis palabras". ${ }^{35} \mathrm{El}$ informe

\footnotetext{
${ }^{33}$ Agencia informativa prensa nacional y extranjera. Averiguar su seriedad, 20 de noviembre de 1924. Fondo Dirección General de Investigaciones Políticas y Sociales. Caja 6, exp. 7, f. 4. AGN, México.

${ }^{34}$ Agencia informativa prensa nacional y extranjera. Averiguar su seriedad. 20 de noviembre de 1924. Fondo Dirección General de Investigaciones Políticas y Sociales. Caja 6, exp. 7, f. 4. AGN, México.

${ }^{35}$ Agencia informativa prensa nacional y extranjera. Averiguar su seriedad. 20 de noviembre de 1924.
}

concluía con estas inequívocas simpatías delahuertistas de la Agencia Informativa Prensa Nacional y Extranjera, aunque no sabemos qué tipo de medidas decidieron tomar las autoridades.

Otra de las agencias investigadas por Gobernación fue la Continental News Service, que se encontraba ubicada en Madero núm. 40 y actuaba como corresponsal de algunos diarios provinciales. "Dicha empresa envía un servicio de noticias por telégrafo diariamente consistente en 758 palabras como mínimo", ${ }^{36}$ explicaba un agente del Departamento Confidencial. Su director era Efraín Salazar Hidalgo, quien después de un tiempo llegó a ser presidente de la Asociación de Periodistas Unidos de América. Y entre sus redactores encontramos al dominicano Darío A. Mañón (1931), quien se destacó como un orador anticlerical vinculado a la masonería y al oficialista Partido Nacional Revolucionario. ${ }^{37}$ También colaboró con la revista Claridad de Buenos Aires y en años posteriores lo vemos trabajando para la United Press.

Antes de continuar es necesario advertir que el carácter comercial o político de las distintas agencias de información no puede ser tajantemente diferenciado. Al contrario, la ideología detrás de cada una de estas iniciativas fue evidente, incluso

Fondo Dirección General de Investigaciones Políticas y Sociales. Caja 6, exp. 7, f. 5. AGN, México.

${ }^{36}$ Continental News Service, investigar las actividades que desarrolla dicha oficina. 27 de febrero de 1935. Fondo Dirección General de Investigaciones Políticas y Sociales. Caja 6, exp. 7, caja 34, exp. 27, f. 3. AGN, México.

${ }^{37}$ Este libro compila una serie de artículos que escribió sobre las condiciones políticas de dichos países. También Mañón (1929). 
en las que se declaraban esencialmente objetivas. Y por otra parte, quienes se definieron primordialmente a partir de sus objetivos políticos, siempre reconocieron que el éxito comercial era una pieza clave de sus proyectos. En este caso la diferencia entre las agencias comerciales y las declaradamente políticas sólo responde a una disyuntiva analítica. Por ejemplo, J. Hernández Támez, director de la comercial Agencia Periodística Latino Americana, cuando en 1928 ofreció sus servicios al presidente Plutarco Elías Calles declaró:

Creo firmemente que este paso que nos hemos decidido a dar, mejorará en algo el acercamiento y comprensión entre los pueblos de nuestra raza, labor que vengo desarrollando desde que fundé nuestra oficina principal, hace cuatro años. ${ }^{38}$

Los intentos empresariales también debieron recurrir a los patrones discursivos que estaban en el ambiente político mexicano.

Por el contrario, un intento de edificar una entidad que mantuviera el carácter latinoamericanista, pero que se transformara en algo rentable para su dueño, fue la Agencia Argos. Reconstruida por el costarricense Amado Chaverri, sin lugar a dudas, retomó las prácticas que previamente había tenido el Centro Mexicano de Informaciones Periodísticas Argos ${ }^{39}$, además abrevó de la experiencia comunicacional que Chaverri había adquirido

${ }^{38}$ Comunica instalación de sucursal. 2 de julio de 1928. Fondo Presidentes Obregón-Calles. Exp. 203a-78, f. 1. AGN, México.

39 Carlos Quiroz suplica proporcionarle copia de informe presidencial. 31 de agosto de 1928. Fondo Presidentes Obregón-Calles. Exp. 217-A-119. AGN, México. durante su participación en La Batalla ${ }^{40}$ y en la edición de sus revistas México y Centroamérica y La Patria Grande. Pero quizá lo que más aportó a su conocimiento del medio fue su paso por el Departamento de Prensa de la Secretaría de Gobernación, donde estuvo seis años trabajando. Esta dependencia gubernamental transmitía boletines telegráficos de noticias, pero a partir de 1926 se había suprimido. De ese modo, el objetivo inicial de Argos fue reemplazarla, dedicándose a transmitir noticias oficiales,

no entraría en competencia con la Oficina de Becerra Acosta puesto que yo me dedicaría, preferentemente, a la selección de declaraciones y de noticias oficiales, mientras Becerra apechugaría con el poutpourri periodístico, sin especializarse ni esmerarse como yo. ${ }^{41}$

A juicio de Chaverri, había que poner particular atención en las noticias que salían al extranjero. En 1932 la Agencia Argos incorporó entre sus servicios corresponsalías por telégrafo, teléfono o correo aéreo. Además, tenía contactos con los periódicos de los estados y cobraba cuotas mensuales de 25 pesos. Según el costarricense:

Nuestra organización es la organización noticiera más poderosa establecida en México. No hay ninguna mejor en el país. Subscríbase si es usted un hombre moderno y quiere estar

${ }^{40}$ Órgano de prensa de la Unión Centro Sudamericana y de las Antillas (UCSAYA).

${ }^{41}$ Carta de Amado Chaverri a Plutarco Elías Calles. 11 de noviembre de 1926. Fondo Plutarco Elías Calles. Exp. 19, inv. 1301, leg. 1, Amado Chaverri Matamoros, f. 43. Fideicomiso Archivo Plutarco Elías Calles y Fernando Torreblanca (FAPECFT), México. 
a tono con la época. Le conviene a Ud. más que a nadie. ${ }^{42}$

En definitiva, todas las iniciativas nombradas anteriormente tuvieron impactos relativamente pequeños, salvo en los grupos culturalmente proclives a la lectura y politizados. A excepción de coyunturas particulares, no alcanzaron despliegues realmente masivos. Carentes de fondos, de continuidad, de profesionales de la información, estaban destinadas a ser fulguraciones repentinas impulsadas por el tesón de sus dueños y gestores. Sin embargo, la situación fue diferente cuando las iniciativas se entroncaron directamente con los objetivos del Estado posrevolucionario.

\section{MÉXICO CONTRA EL IMPERIALISMO INFORMATIVO}

Las tres principales entidades vinculadas estrechamente con el gobierno mexicano fueron la Agencia Trens, la Agencia Ariel y la Agencia Duems. Todas recibieron apoyos financieros estatales, soporte profesional, la posibilidad de acceder a las estructuras gubernamentales y subvenciones telegráficas para que pudieran funcionar evadiendo los altos costos que ello implicaba. La primera se orientó a Estados Unidos, la segunda a Centroamérica y la última se relacionó con la información europea. A este selecto grupo debemos sumar dos agencias con las que compartieron el espacio comunicacional en distintos

42 Carta de Amado Chaverri a Plutarco Elías Calles. 11 de noviembre de 1926. Fondo Plutarco Elías Calles. Exp. 19, inv. 1301, leg. 1, Amado Chaverri Matamoros, f. 55. FAPECFT, México. periodos. Entre 1927 y 1928 encontramos a la Agencia Mexicana de Prensa que fundó Francisco de A. Benavides, pero que fue impulsada directamente por Luis $\mathrm{N}$. Morones mientras dirigía la Secretaría de Industria. ${ }^{43}$ Y en 1929, frente a la desaparición de la Agencia Ariel, el gobierno mexicano decidió impulsar la ya mencionada Agencia Argos para cubrir el espacio vacío, aunque esta nunca llegó a reemplazar su labor.

Veamos en primer lugar el caso de la agencia Duems.

Duems Agency News fue quizá la más enigmática de las tres agencias impulsadas por el gobierno. El periodista radical estadunidense, Carleton Beals, la describía en 1925 con las siguientes palabras:

Duems Agency (german semi-official free telegraphic news-service) reports a reapproachment between German and Russia, but the item is not at all informative in that the same information has been published at greater lenght in the American papers. ${ }^{44}$

El periodista desconocía que la agencia estaba más vinculada al gobierno mexicano que a su par alemán y que mucha de la información que distribuía no era generada por corresponsales propios, sino por

${ }^{43}$ Esta agencia contaba con corresponsales en Colombia, Venezuela, Perú, Argentina y Cuba, basándose fundamentalmente en las redes de la Confederación Regional Obrera Mexicana (CROM). Véase Agencia Mexicana de Prensa. 24 de octubre de 1927. Fondo Presidentes Obregón-Calles. Exp. 721-I-6. AGN, México.

${ }^{44}$ Carta de Carleton Beals a Lyons. 15 de octubre de 1925. Fondo Dirección General de Investigaciones Políticas y Sociales. Caja 7, exp. 3, f. 21. AGN, México. 
instancias gubernamentales mexicanas. "Dichos mensajes pueden darse [a la] prensa firmándolos por Agencia Duems", ${ }^{45}$ explicaba una nota gubernamental en 1922. De ese modo, esta entidad servía directamente para que las autoridades mexicanas disfrazaran su propia información detrás de una empresa privada.

Los inicios de esta entidad son poco claros y los motivos de la presencia de su director, Karl Duems, en México, tampoco podemos establecerlos con certeza. ${ }^{46}$ La agencia se presentaba extensamente como "Servicio mundial de prensa cablegráfico e inalámbrico. Servicio de asuntos mexicanos para la prensa de la Europa central. Única oficina mediadora y transmisora para el servicio destinado a la América Latina." 47

Pero basó su accionar en transmitir la información que las autoridades mexicanas estimaran conveniente a los periódicos de Europa central adheridos a sus servicios.

Así solemos proceder -explicaba Duems en 1926- cuando se trata de importantes intereses de México, para contrarrestar las noticias tendenciosas y perjudiciales a México que constantemente se publican

45 Telegrama de la Secretaría de Relaciones Exteriores a la legación mexicana en Guatemala. 4 de agosto de 1922. Leg. 18-12-43, f. 6. AHSRE, México.

46 Podemos encontrar a este periodista inmerso en un confuso incidente policial a fines de 1922. Véase González (1989). Una posible interpretación de la cercanía entre México y Alemania en Murphy s(1997).

${ }^{47}$ Subvención a la Agencia de Publicidad Duems para que continúe su servicio de información para la propaganda a favor de México en Berlín, Alemania. 5 de enero de 1923. Leg. 35-30-41, f. 7. AHSRE, México. en Europa, de procedencia generalmente malévola. ${ }^{48}$

Con esta misma lógica, entregaba cables con información europea a los periódicos mexicanos y centroamericanos. La Secretaría de Relaciones Exteriores se encargaba de traducir directamente mucha de la información que distribuía. Y también desarrolló, a través de la embajada en Alemania, una serie de publicaciones que buscaban divulgar la labor política del gobierno (Agencia Duems, 1923). ${ }^{49} \mathrm{El}$ hermano de Karl, Erich, fue el encargado de la agencia en Berlín.

Sobre esta entidad, en agosto de 1922 Juan de Dios Bojórquez, entonces embajador en Guatemala, escribió que al principio fue una forma de aparentar que las noticias provenían de una instancia particular, y que incluso llegó a recomendar sus servicios al gobierno guatemalteco, con el objetivo de "intensificar una corriente informativa” entre ambos países. Sin embargo, antes de incrementar sus gestiones se reunió con Adrián Recinos, periodista de Excélsior de Guatemala, uno de los medios que destacaba por su crítica al curso que había adquirido la revolución mexicana. Las palabras de Recinos, futuro secretario de Relaciones Exteriores de Guatemala, para referirse a la Agencia Duems fueron categóricas. La acusó de hacer propaganda a favor de Alemania y en contra de los aliados, lo que para él era muy lamentable si se consideraba que

${ }^{48}$ Memorándum de la secretaria particular de la Presidencia al secretario de Relaciones Exteriores, Aarón Sáenz. 6 de septiembre de 1926. Leg. 18-5184, f. 1. AHSRE, México.

${ }^{49}$ Este tipo de relación también podemos encontrarla con la Deutsche Welle. Véase Roldán (2009).

\section{()(1)}


tenía su base de operaciones en México. Después de este encuentro, Bojórquez se preguntaba si no había sido "una protesta velada que parecía indicar que sospechaba, pero sin estar de ello seguro, que la Agencia Duems era apoyada por el gobierno mexicano". ${ }^{50}$ Con estas palabras, el diplomático comenzaba su exposición en contra de la Agencia, llegando a mencionar que "el sentimiento general aquí, es de casi completa incredulidad para las noticias que proceden de la Agencia Duems; el público las califica de bluffs". 51

Definitivamente, la política antialemana que llevaba a cabo el gobierno guatemalteco impactaba directamente en la efectividad de la estrategia comunicacional mexicana. De ese modo, la postura de Bojórquez era que se debía crear una nueva entidad, llamada Agencia de Informaciones Inter-Americanas, evitando vincularla nuevamente al gobierno, para evadir "la desconfianza en los diarios y las suspicacias en el público". ${ }^{52}$ Esto no significaba romper todos los lazos con la Agencia Duems, sino reorientar su trabajo fuera del escenario centroamericano.

De hecho, este organismo continuó publicando en Europa su boletín deno-

${ }^{50}$ Carta de Juan de Dios Bojórquez al secretario de Relaciones Exteriores de México. 9 de agosto de 1922. Leg. 18-12-43, f. 1. AHSRE, México. El embajador de Francia en Guatemala realizó la misma crítica en contra de la agencia. De la ciudad de México se le encomendó a Bojórquez hacer una enfática separación entre lo que publicaba la agencia y el gobierno.

${ }^{51}$ Carta de Juan de Dios Bojórquez al secretario de Relaciones Exteriores de México. 9 de agosto de 1922. Leg. 18-12-43, f. 2. AHSRE, México.

${ }^{52}$ Carta de Juan de Dios Bojórquez al secretario de Relaciones Exteriores de México. 9 de agosto de 1922. Leg. 18-12-43, f. 2. AHSRE, México. minado Latein-Amerika-Dienst, y en noviembre de 1922 reconocía que "cumpliendo con las instrucciones recibidas de México, hemos dado pues un paso para intensificar todavía más por medio del servicio mencionado nuestra labor en pro de los intereses mexicanos". ${ }^{53}$ Erich Duems desde Alemania reconocía que los principales diarios de la región estaban afiliados a sus servicios, por lo que podían emplear un método "directo y preventivo”, para que las mismas redacciones reconocieran las noticias tendenciosas.

Hemos logrado -destacaba- que la prensa alemana considere toda noticia procedente de Estados Unidos sobre México con escepticismo y que en general recurra para su información a nuestros servicios mexicanos. ${ }^{54}$

La agencia también se había dedicado a realizar publicaciones especiales, a gestionar entrevistas con los diplomáticos mexicanos, a organizar conferencias e, incluso, había entregado noticias en Europa occidental. Después de una carta de recomendación del embajador en Alemania, Alfredo Caturegli, a principios de 1923 la Secretaría de Relaciones Exteriores decidió continuar entregándoles 500 pesos mensuales para que pudieran desarrollar su labor.

\footnotetext{
${ }^{53}$ Subvención a la Agencia de Publicidad Duems para que continúe su servicio de información para la propaganda a favor de México en Berlín, Alemania. 25 de noviembre de 1922. Leg. 35-30-41, f. 1. AHSRE, México.

${ }^{54}$ Subvención a la Agencia de Publicidad Duems para que continúe su servicio de información para la propaganda a favor de México en Berlín, Alemania. 25 de noviembre de 1922. Leg. 35-30-41, f. 2. AHSRE, México.
} 
Volviendo a Centroamérica, para fines de agosto de 1922 el mismo Bojórquez había transformado sus ideas, con ayuda de Juan Novell Ruiz, en el "Proyecto para organizar un servicio de noticias de México”. A grandes rasgos, propuso la creación de una empresa que "podría tener (aparentemente) oficina y corresponsales en Nueva York y presentar en su título una cabeza que diera a entender su procedencia norteamericana". ${ }^{55} \mathrm{La}$ sede en Nueva York, a juicio del diplomático, podría ser dirigida por uno de los representantes de los diarios mexicanos en aquella ciudad. Mientras que el director real de la agencia estaría en la ciudad de México y debería ser alguien que conociera tanto la realidad centroamericana como las necesidades del gobierno mexicano. Bojórquez propuso para esta labor al hondureño Rafael Heliodoro Valle. Una tercera oficina debería instalarse en Guatemala para despachar informaciones desde Centroamérica a México y Estados Unidos, la cual podría ser creada en sociedad con el gobierno guatemalteco. Finalmente, la propuesta concluía planteando que todas las operaciones comerciales de la nueva agencia deberían hacerse en divisas mexicanas, con el objetivo de comenzar a introducir el peso en la región.

En noviembre de 1922 este proyecto, con algunos cambios, estaba prácticamente convertido en realidad. Solamente faltaba designar al encargado en Guatemala. La proyectada Agencia de Informaciones Inter-Americanas, se transformó a comienzos de 1923 en la Ariel News Service. Su objetivo fue principalmente

55 Proyecto para organizar un servicio de noticias de México para Centroamérica. 29 de agosto de 1922. Leg. 18-12-45, f. 1. AHSRE, México. generar informaciones sobre México y Centroamérica, para ser distribuidas en el mundo. ${ }^{56}$ En palabras del costarricense Rafael Cardona, quien finalmente fue designado como su organizador, "Ariel, recibía el apoyo de los más importantes diarios del istmo y estaba consagrada a 'producir espíritu de verdad en Centroamérica respecto a la política mexicana y mundial"” (Díaz, 2008, p. 134). ${ }^{57}$

En principio la entidad fue proyectada como una oficina de información, y el cargo que ocupó Cardona fue comisionado de publicidad mexicana de la Secretaría de Relaciones Exteriores en Centroamérica. Pero para evitar que la agencia se considerara como un departamento oficial se construyó una fachada empresarial. Así, las autoridades diplomáticas mexicanas en Guatemala cuidaron los mínimos detalles para no evidenciar su real origen

consecuente con sus indicaciones en el sentido de que el viaje del Sr. Cardona aparezca como de carácter particular, he hecho figurar como gastos por servicio de automóviles la cantidad de 75.00 dls. (setenta y cinco) que le ministré, ${ }^{58}$

explicaba Juan de Dios Bojórquez al secretario de Relaciones Exteriores en un memorándum reservado. En el fondo se

\footnotetext{
${ }^{56}$ Véase Expediente personal de Rafael Cardona. 1923-1934. Exp. 4-9-63. AHSRE, México.

${ }^{57}$ Citando El Imparcial, 5 de septiembre de 1923, Guatemala. Cardona también fue el encargado de coordinar la presencia de periodistas centroamericanos en el Congreso Internacional de Periodistas, que se efectuó en Mérida, Yucatán, en 1923.

${ }^{58}$ Gastos de viaje para el señor Rafael Cardona. 16 de febrero de 1923. Exp. 4-9-63, f. 2. AHSRE, México.
}

\section{()(1)}


trataba de evitar que los periódicos locales fueran escépticos a la información de la agencia, especialmente El Imparcial, crítico de los primeros gobiernos posrevolucionarios, y que los agentes estadunidenses no consideraran la iniciativa como orquestada desde la ciudad de México.

De todas maneras, la embajada de Estados Unidos en Guatemala y sus funcionarios de inteligencia acusaron a la agencia de tener una disposición "poco amistosa" con su país, especialmente en el contexto de la intervención de los marines en Nicaragua. ${ }^{59}$

El propio Bojórquez desglosó en 1923 los gastos que realizaba la embajada en la sustentación de la Agencia Ariel. Cincuenta dólares fueron destinados a la instalación inicial, mientras que mensualmente se erogaban quince en la renta de la sede y 25 en el sueldo del empleado, Rafael Cardona. ${ }^{60}$ Los gastos operativos de la agencia debían resolverse mediante la venta de información a los medios locales y a los periódicos mexicanos. Aunque también recibía un subsidio para poder usar las redes telegráficas y así disminuir sus costos.

En la ciudad de México, el periodista Pablo Sánchez de El Demócrata era uno de los principales encargados de mantener la comunicación con el despacho en Guatemala. Este redactor concurría diaria-

\footnotetext{
59 Memorándum al secretario de Estado. 14 de marzo de 1928. Records of the Department of State Relating to Internal Affairs of Mexico, 1910-1929. Microcopy 274, rollo 138. The National Archives of Washington.

${ }^{60}$ Después de desempeñar esta labor, y trabajar en el periódico El Imparcial de Guatemala, Cardona fue jefe del Departamento Internacional de Prensa de la Presidencia de la República de Guatemala.
}

mente a la oficina del correo a depositar personalmente los cables. En abril de 1923, Julio Martínez Trens, director de la agencia que llevaba su apellido, se encontró con Sánchez en dicha oficina y vio cómo desarrollaba su trabajo. Desde ese momento, Trens se esmeró por conseguir para su agencia todas las facilidades que poseían sus pares semioficiales.

El caso de la Agencia Trens no involucró el control directo por parte de las autoridades estatales. Al contrario, la autonomía fue una de las claves en su funcionamiento. El origen incierto de esta agencia podemos encontrarlo en una de las primeras peticiones que realizó su creador al gobierno mexicano:

Comisionado por el Estado Mayor Presidencial para atender y acompañar al periodista americano Mr. William Randolph Hearst durante su viaje a nuestra república, el eminente escritor de que se trata me hizo especial invitación para que fuera yo un eslabón entre nuestro Gobierno y la prensa que dirige. $^{61}$

Con este motivo, el periodista solicitó un puesto en el consulado de Nueva York, pero el propio Genaro Estrada le respon-

${ }^{61}$ Carta de Julio Martínez Trens al secretario de Relaciones Exteriores. 30 de noviembre de 1921. Leg. 6-15-212, f. 1. AHSRE, México. Trens fue intérprete del magnate estadunidense y además este le encomendó darle un mensaje oral al presidente Obregón. Hearst le pedía autorización para que algunos de sus periodistas visitaran México, además se comprometía a despedir a quienes el gobierno mexicano considerara que informaban de mala fe. Carta de Julio Trens a Fernando Torreblanca, secretario de la Presidencia. 25 de noviembre de 1921. Fondo Presidentes Obregón-Calles. Exp. 104-p-103. AGN, México. 
dió que por el momento no había plazas vacantes. Sin embargo, el gobierno mexicano no dejaría pasar las posibilidades de acercarse al magnate estadunidense, quien además era uno de los principales críticos de la situación mexicana a través de los medios que controlaba.

Desde 1923 esta agencia comenzó a recibir el mismo tratamiento que Ariel, incluyendo exenciones telegráficas, "por tratarse de una oficina de propaganda a favor de nuestro país". ${ }^{62}$ Su relación con el gobierno se caracterizó por la constante negociación sobre franquicias y funciones, en lugar de la simple dependencia que enfrentaron las entidades mencionadas anteriormente. ${ }^{63}$ De hecho, muchas de las respuestas que recibió Trens por parte del ejecutivo estuvieron condicionadas a determinadas negociaciones. ${ }^{64}$ Incluso esta agencia llegó a enfrascarse en discusiones sobre la libertad de prensa con el gobierno, cuando este decidió prohibirle despachar información sobre las elecciones presidenciales de $1923 .{ }^{65} \mathrm{Sin}$ embargo, estos desencuentros concluyeron hacia finales de la década con la creación de una alianza estratégica, que convirtió a la Agencia Trens prácticamente en el órgano infor-

62 Solicitud de la Agencia Mexicana Trens a la Secretaría de Comunicaciones y Transportes, sobre franquicia telegráfica. 8 de agosto de 1923. Leg. 3530-3, f. 2. AHSRE, México.

${ }^{63}$ Julio Trens suplica enviarle copia de los boletines que expida esta Secretaría Particular. 30 de agosto de 1928. Fondo Presidentes Obregón-Calles. Exp. 721-c-16. AGN, México.

${ }^{64}$ Memorándum de Álvaro Obregón a Julio Trens. 3 de mayo de 1928. Fondo Presidentes Obregón-Calles. Exp. 824-T-4. AGN, México.

65 Telegrama de Julio Trens a Álvaro Obregón, 24 de octubre de 1923, Fondo Presidentes ObregónCalles. Exp. 824-T-4. AGN, México. mativo de la Secretaría de Relaciones Exteriores. Esto permitió que su boletín noticioso, Mexican Daily News, tuviera tirajes mensuales cercanos a los 100000 ejemplares (Secretaría, 1930).

Para el gobierno, el objetivo de mantener su relación con la Agencia Trens fue introducir noticias mexicanas directamente en los medios estadunidenses y a su vez, filtrar las noticias que desde Estados Unidos llegaran a los diarios mexicanos. Esta agencia se ubicaba en Colón núm. 43, y la mayoría de la información que ofrecía a los diarios mexicanos citaba a los cónsules del país, quienes desmentían rumores de preparación de invasiones rebeldes o simplemente describían negativamente las acciones de los opositores exiliados. En el servicio contratado por la Secretaría de Gobernación se hacía un especial énfasis en la opinión que ciertas acciones del gobierno generaban entre los medios de comunicación estadunidenses. Esto en términos prácticos significaba la realización de una labor de monitoreo de las actividades de los delahuertistas, gomecistas, escobaristas y todos aquellos que tuvieron que irse de México después de algún levantamiento. "[La ciudad de Laredo] es hoy por hoy el centro donde se dan cita todas las informaciones dolosas con respecto a México y los sucesos que han conmovido al país", 66 explicaba, en 1927, Julio Trens al oficial mayor de la Subsecretaría de Gobernación.

La agencia servía para intentar controlar las informaciones que se distribuían

${ }^{66}$ Julio Trens. Solicita ayuda para sostener la Agencia informativa que lleva su nombre. 15 de octubre de 1927. Fondo Dirección General de Investigaciones Políticas y Sociales. Caja 34, exp. 55, f. 6. AGN, México. 
entre México y Estados Unidos, en ambos sentidos. Aunque las distintas agencias internacionales y los corresponsales extranjeros limitaban que su objetivo se cumpliera a cabalidad, esto no detuvo las intenciones de su director. En las palabras del agente de Departamento Confidencial de Gobernación, Eduardo Mendoza Ramírez, podemos observar el tipo de función que desempeñaba:

El Sr. Julio Trens de la Agencia Trens News Service, ha escrito algunos artículos refutando la opinión del Sr. [Carleton] Beals... escrito en inglés, tratando en la actualidad el Sr. Trens de enviarlo a la mayor parte de los periódicos que se editan en los Estados Unidos [...] con el objeto de refutar la opinión que el Sr. Beals tiene de México y sus partidos políticos. ${ }^{67}$

La intervención directa de Trens fue un caso excepcional, pues la mayoría de las veces la fachada institucional de la agencia cumplía con esta función. ${ }^{68}$

Este tipo de actividades de contención no podía desplegarse cada vez que un periodista osara cuestionar el desarrollo político del México posrevolucionario, pues la lógica del "desmentido" tenía escaso poder propagandístico. Por este motivo, en 1927 Trens propuso que las oficinas de su agencia se instalaran en el "centro" de la ciudad, que pasaran de la calle Colón, cerca de El Universal y Excél-

${ }^{67}$ Se informa sobre las actividades a que se dedica el señor Carleton Beals. 12 de agosto de 1931. Fondo Dirección General de Investigaciones Políticas y Sociales. Caja 63, exp. 3, f. 109. AGN, México.

${ }^{68}$ Mexican Newspaperman Replies to Carleton Beals. Mexican Daily News, agosto de 1931, México, p. 1. sior, a la avenida Madero, "donde los periodistas americanos tendrán máquinas para escribir, papel, útiles, etc., de tal modo que sea esta Agencia para ellos un centro de confianza al cual miren como su propia casa”. ${ }^{69}$ De ese modo, Trens podría influir directamente en ellos, explicándoles las razones de las medidas que tomaba el gobierno y evitando que las confusiones y malos entendidos fueran publicados en el extranjero. "Tengo la ventaja de ser amigo de todos ellos", recalcaba el director. Con tal motivo solicitó 500 pesos a las autoridades de gobernación.

En esas mismas fechas se redactó un interesante memorándum que proponía una serie de medidas para controlar a los corresponsales extranjeros una vez que llegaran al país. El autor, no identificado, aunque reconoce haber trabajado por nueve años en la prensa, establecía que:

Por regla general, cuando los corresponsales son designados por primera vez para México, saben muy poco, si no es que nada, acerca de México o de sus condiciones, y necesitan varios meses para adaptarse al medio y familiarizarse con él. ${ }^{70}$

${ }^{69}$ Julio Trens. Solicita ayuda para sostener la Agencia informativa que lleva su nombre. 15 de octubre de 1927. Fondo Dirección General de Investigaciones Políticas y Sociales. Caja 34, exp. 55, f. 7. AGN, México. Probablemente la agencia atravesaba por alguna crisis económica, pues al año siguiente la encontramos fusionada con la Agencia Argos. Véase, Carta de la revista Patria Grande a Manuel Barros Castellón, embajador de Chile en México. 6 de julio de 1929. Leg. 1153a, sin foliar. Archivo Histórico del Ministerio de Relaciones Exteriores de Chile (AHMrReE), Chile.

${ }^{70}$ Corresponsales de periódicos. 1927 (sin fecha exacta). Fondo Dirección General de Investigaciones Políticas y Sociales. Caja 24, exp. 32, f. 1. AGN, México. 
El problema era que la primera fuente de información que buscaban los recién llegados apuntaba hacia el cuerpo diplomático de sus respectivos países, el cual siempre tenía intereses políticos en juego. De hecho, a juicio del autor "hay una minoría, sin embargo, cuyas ambiciones y esfuerzos están capitalmente dirigidos a crear una falsa impresión respecto a las condiciones que existen en la república" ${ }^{71}$ Este sector sólo ve las características negativas, y contacta a los periodistas con los enemigos de México.

En muchas ocasiones -continúa- las agencias de noticias, no saben a dónde encaminarse para obtener informes verídicos, sin que les sea difícil obtener informaciones falsas o noticias amarillistas, y en muchas ocasiones, esas mismas agencias son utilizadas por intereses antagónicos, en vez de serlo para una propaganda benéfica y constructiva. ${ }^{72}$

La propuesta concreta del autor era que el gobierno federal fundara y administrara un Club de la Prensa, donde los corresponsales pudieran ser controlados. El espacio proyectado sería un lugar exclusivo, donde los periodistas pudieran escribir tranquilamente, comer algún almuerzo, e incluso, en la tarde disfrutar alguna "copa bebida con quietud". Los gastos deberían ser financiados por los mismos miembros, pues según el autor no había

${ }^{71}$ Corresponsales de periódicos. 1927 (sin fecha exacta). Fondo Dirección General de Investigaciones Políticas y Sociales. Caja 24, exp. 32, f. 1. AGN, México.

${ }^{72}$ Corresponsales de periódicos. 1927 (sin fecha exacta). Fondo Dirección General de Investigaciones Políticas y Sociales. Caja 24, exp. 32, f. 2. AGN, México. que olvidar que los corresponsales estaban muy bien pagados. Las distintas dependencias del gobierno entregarían directamente boletines con información a los miembros del Club.

El objetivo del Club consistiría en ayudar a la administración central a la propagación y sostenimiento de sus planes para el desarrollo de México, por medio de una información inteligente y una benéfica propaganda. $^{73}$

En definitiva esto permitiría disminuir el desequilibrio existente entre México y Estados Unidos. Esta concepción de la desigualdad entre ambos países, pero que en muchos casos incluía fuerte dosis de complementariedad, fue la clave para entender todos los esfuerzos que se hicieron desde México a nivel propagandístico (Serna, 2010).

No sabemos hasta qué punto se concretó esta iniciativa, pero otra instancia, el Club de Corresponsales Extranjeros, comenzó a funcionar en la ciudad de México en esos mismos años. ${ }^{74}$ De todas maneras, debemos considerar que el mundo de los corresponsales de diarios estadunidenses en México no era muy amplio, de hecho, el mismo Trens en 1927 entregó a Gobernación una lista que incluía solamente seis nombres. Entre estos, encontramos a Douglas Grehan,

${ }^{73}$ Corresponsales de periódicos, 1927 (sin fecha exacta). Fondo Dirección General de Investigaciones Políticas y Sociales. Caja 24, exp. 32, f. 5. AGN, México.

${ }^{74}$ Chicago Daily Tribune. Investigar dirección y antecedentes del corresponsal de dicho periódico. 1931. Fondo Dirección General de Investigaciones Políticas y Sociales. Caja 34, exp. 25. AGN, México. 
quien reporteaba para el Daily Herald y el Daily Express de Londres; Harry Nichols del New York Times; Arthur Constantine del The New York World y The New York Evening World; Clarence DuBose de la Associated Press; Jack Starr Hunt de The New York Herald Tribune y Los Angeles Times; Ernest Fine de United Press; y John H. Cornyn de The Chicago Tribune. A este reducido número se agregaban los periodistas de los medios de la izquierda radical, como Carleton Beals, de The Nation o Joseph Freeman de la Agencia Soviética TASS, quienes se caracterizaban por su itinerancia y movilidad (Britton, 1995). ${ }^{75}$ La cifra se terminaba con los escasos representantes de los periódicos latinoamericanos. Por lo tanto, las intenciones de control que se ejercieron sobre los periodistas estaban dentro de las posibilidades prácticas del Estado mexicano. Sin embargo, la mayor parte del tiempo los reporteros fueron capaces de evadir los mecanismos de control e informar lo que ellos consideraban pertinente.

Finalmente, en los esbozos que hizo el gobierno mexicano para manejar, en lo posible, los flujos de información internacional, las tres agencias reseñadas debían actuar de manera coordinada. Por ejemplo, en muchos casos, la Agencia Ariel entregó informaciones sobre Europa a los periódicos centroamericanos, las cuales obtenía directamente de la Agencia Duems. Lo mismo sucedía en cuanto Trens entregaba noticias centroamericanas en Estados Unidos, y así sucesivamente. ${ }^{76}$ Hacia

\footnotetext{
${ }^{75}$ Britton denomina a este grupo como literatos "bohemios" que llegaban a México en busca de las perspectivas revolucionarias.

${ }^{76}$ Este entrelazamiento también se extendía a los "activistas". Por ejemplo, Jolibois Fils, era el repre-
}

1930 , esta agencia imprimía su boletín Mexican Daily News, en inglés y español (unos 75000 ejemplares mensuales) (véase Secretaría, 1930) y al mismo tiempo transmitía un reporte noticioso a través de la estación XDA, vinculada a la Secretaría de Relaciones Exteriores. ${ }^{77}$

Este entrelazamiento noticioso era clave no sólo para abaratar los costos, sino para crear un sentido de verosimilitud y extender las redes informativas lo más ampliamente posible. Podemos establecer que las intenciones de los gobiernos posrevolucionarios fueron instaurar un verdadero "frente" informativo que cuestionara los procesos hegemónicos desarrollados por los espacios de comunicación estadunidenses. Esta construcción gubernamental se basó precisamente en asumir parte del discurso sobre la libertad de expresión y la necesidad de crear conexiones globales para establecer múltiples alternativas al propio esquema dominante.

\section{El DECLIVE}

El manejo de la información ha sido siempre un punto sensible en los procesos políticos. De ese modo todos los actores implicados se movían en un escenario inestable, que podía volverse rápidamente en contra, dependiendo de la coyuntura. La utilidad de quienes manejaban la infor-

sentante en las Antillas de la Agencia Trens. Véase, Correspondencia de Rafael Heliodoro Valle con Jolibois Fils. Fondo Rafael Heliodoro Valle. Exp. 1093, doc. 5. Frunam, México.

77 Telephone Broadcast of Mexican Daily News from Station XDA the Most Powerful in Latin America. Mexican Daily News, 11 de septiembre de 1930, México, p. 1. 
mación y la propaganda podía transformarse violentamente en una amenaza para los intereses que estaban detrás de estos procesos. Una palabra errónea, una frase poco certera, podía cambiar las simpatías de las autoridades y significar una debacle para los periodistas e informadores.

El final de muchas de las agencias desaparece de las fuentes. Evidentemente la mayoría de ellas después de su tiempo de fulgor, dejó de aparecer en el primer plano. Precisamente, una de las características de este tipo de entidades es mantenerse en un segundo lugar, aunque en muchas ocasiones son las que dan cuerpo a las informaciones periodísticas. Desde la trastienda de los diarios y revistas, apenas podemos percibir cuándo dejaron de ser útiles, cuándo se transformaron en estorbos. Por ejemplo, casi no hay rastros sobre la desaparición de la Agencia Duems, sólo tenemos un breve obituario aparecido en un periódico español:

Fallecimiento de un periodista alemán. Berlín 20 [de septiembre de 1927]. El Sr. Karl Duems, fundador y director del Servicio de Prensa alemán para Méjico, América Central y América meridional, que se hallaba en Berlín por motivos de salud, ha fallecido a la edad de cincuenta y dos años. ${ }^{78}$

En algunos casos, minoritarios, estas entidades salieron del escenario público entre estruendosos conflictos. La agencia de Amado Chaverri publicó una noticia en 1927 donde se aseguraba que en una discusión en el Senado habían salido a relucir pistolas. Esta frase significó graves problemas para el periodista, cuando el

${ }^{78}$ Fallecimiento de un periodista alemán. La Libertad, 21 de septiembre de 1927, Madrid, p. 3. entonces gobernador de Monterrey, Aarón Sáenz, puso la mirada sobre su trabajo. A juicio del entonces aspirante a la presidencia, la información que el costarricense proporcionaba "carece de la seriedad que debe tener, tratándose, como seguramente se trata, de una agencia en relaciones con oficinas del gobierno". ${ }^{79}$ La respuesta del ejecutivo, para evitar un conflicto con el gobernador, fue simplemente suprimir dicho servicio. Chaverri debió reenfocar la Agencia Argos hacia el extranjero, y sólo el apoyo decidido de Plutarco Elías Calles le permitió sobrevivir económicamente. Sin embargo, cuando el poder del Jefe Máximo comenzó a decaer, Chaverri fue uno de los primeros en quedar a la deriva. La estrecha relación entre las agencias, los corresponsales y los periodistas, con las dinámicas políticas del Estado fue tanto la causa de su éxito, como posteriormente el motivo de su fracaso.

A comienzos de la década de 1930 la información extranjera generada por actores locales fue rápidamente reemplazada por la que provenía directamente de los consorcios estadunidenses. La inminente caída del cártel de las agencias informativas internacionales que se había formado en el siglo XIX, dejó definitivamente el escenario abierto y sin contrapesos para las entidades estadunidenses. Además, la normalización de las relaciones diplomáticas entre México y Estados Unidos significó que la competencia comunicacional ya no era un elemento prioritario para las autoridades mexicanas, por lo que su inversión directa en las agencias se redujo.

79 Memorándum de Aarón Sáenz a Fernando Torreblanca. 19 de octubre de 1927. Fondo Presidentes Obregón-Calles. Exp. 721-ch-10, f. 1. AGN, México. 
Para 1931, la Agencia Trens, que se había convertido en una dependencia más de la Secretaría de Relaciones Exteriores, hizo circular en Estados Unidos un aviso de El Nacional, el periódico del partido oficial. En este se establecía que: "In Mexico the newspaper situation has changed." 80 Ahora el país representaba un mercado ideal para el vecino del norte y $E l$ Nacional ponía a su disposición no sólo su circulación a escala nacional, sino además el hecho de que sus lectores eran parte de una organización que buscaba el bienestar de México.

En este contexto, en febrero de 1934 la Secretaría de Gobernación envió una circular estableciendo que: "El C. oficial mayor en acuerdo de esta fecha dispuso que a partir del día de hoy, se suspenda el servicio de recortes de periódicos que estaba enviando la agencia Argos." ${ }^{81}$ Con este tipo de memorándums se ponía fin a los aportes estatales a las agencias de información extranjera durante este periodo. ${ }^{82}$ También se cerraba la etapa donde este tipo de instituciones había sido crucial para los objetivos políticos de los gobiernos posrevolucionarios.

80 [Aviso comercial inserto en] Mexican Newspaperman Replies to Carleton Beals. Mexican Daily News, agosto de 1931, México, p. 1.

${ }^{81}$ José M. Moreno. Solicita ayuda para continuar publicando su Revista Argos. 16 de febrero de 1934. Fondo Dirección General de Investigaciones Políticas y Sociales. Caja 34, exp. 54, f. 3. AGN, México.

${ }^{82}$ No hay mucha claridad de cuándo dejaron de funcionar cada una de las agencias. Algunas sobrevivieron pese a la carencia de apoyo estatal. Por ejemplo, en 1936 todavía se menciona que la Agencia Trens transmite informaciones hacia Chile. Véase, Observaciones sobre el servicio de noticias telegráficas de la Agencia Trens. 24 de agosto de 1936. Leg. III-329-28, f. 1. AHSRE, México.
La mayoría de los periodistas estadunidenses, que habían sido clave en las campañas publicitarias, comenzaron a mostrarse críticos del devenir político mexicano. Algunos simplemente optaron por abandonar el país antes de que se les aplicara el fatídico artículo 33 constitucional. Para el año 1930, el estadunidense Carleton Beals, el boliviano Tristán Marof, el chileno Luis V. Cruz, entre otros, habían sido expulsados de México. Se los acusaba de inmiscuirse en la política local, algo que los extranjeros tenían prohibido.

Algunos de los periodistas citados anteriormente siguieron rumbos muy diferentes. Por ejemplo, Rafael Cardona, nacionalizado mexicano, después de trabajar para el general Jorge Ubico, dictador de Guatemala, se dedicó a realizar actividades de intriga política en Costa Rica, su país natal. "Por todo lo anterior habrá que estudiar muy detenidamente el caso del señor Cardona en lo que se refiere a su ciudadanía mexicana", 33 exponía J. M. Puig Casauranc al ministro mexicano en Nicaragua, Pablo Herrera de la Huerta. El otrora hombre central en las estrategias comunicativas del gobierno mexicano se había transformado en 1934 en una importante molestia en la política de México hacia Centroamérica. Algo no poco común entre quienes habían desempeñado funciones confidenciales.

Los sindicatos de la prensa consolidaron su poder, dirigiendo incluso algunos de los periódicos más importantes del país. Si bien los extranjeros habían sido recibidos a regañadientes por los rotativos locales, a partir de estos años las posibilida-

${ }^{83}$ Memorádum de J. M. Puig Casauranc a Pablo Herrera de Huerta. 29 de junio de 1934. Leg. 4-9-63, f. 64. AHSRe, México. 
des de que periodistas no mexicanos se desempeñaran en estos espacios fueron cada vez más escasas. El hondureño Rafael Heliodoro Valle, que era uno de los principales redactores del medio local, carta tras carta desilusionaba a sus amigos periodistas centroamericanos que pretendían venir a México. A su juicio, el control por parte de los sindicatos había convertido en algo casi imposible que un extranjero desconocido fuera contratado. ${ }^{84}$

\section{CONCLUSIONES}

Es necesario destacar que los sucesivos gobiernos posrevolucionarios rechazaron sistemáticamente la posibilidad de crear una agencia gubernamental. ${ }^{85}$ Ninguna institución parecida al Departamento Autónomo de Prensa y Publicidad (DAPP) creado durante el gobierno de Lázaro Cárdenas, fue gestada entre 1920 y 1934 . Al contrario, la eficacia de la propaganda pasó necesariamente por la posibilidad de disfrazar el origen de la información detrás de una fachada independiente y empresarial. Este tipo de construcción indirecta nos muestra que los límites de la disputa

${ }^{84}$ Véase por ejemplo, Correspondencia de Rafael Heliodoro Valle con José R. Castro. 1933. Fondo Rafael Heliodoro Valle. Exp. 446. FrunAm, México. También, Correspondencia de Rafael Heliodoro Valle con Benjamín Carrión. 1934. Fondo Rafael Heliodoro Valle, exp. 413. FRUNAM, México.

${ }^{85}$ En 1927 Borja Bolado propuso la creación de una entidad que lograra coordinar todo el esfuerzo comunicacional propagandístico del gobierno. La iniciativa fue rechazada tajantemente por el ejecutivo. Agencia Informativa de la Presidencia de la República. Proyecto. 23 de noviembre de 1927. Fondo Presidentes Obregón-Calles. Exp. 711-a-50. AGN, México. no estaban puestos necesariamente en las prácticas políticas estatales, sino que se orientaban a situaciones vinculadas por la hegemonía y la instauración de un sistema de dominación. Así, las agencias se transformaron en un eslabón más del frente cultural creado para defender los alcances de la revolución mexicana.

En el cuerpo de este texto se mencionaron cerca de doce entidades destinadas a difundir y construir noticias extranjeras con sede en México: Ariel News Service, Agencia Mexicana Trens, Agencia Duems, Agencia Informativa Prensa Nacional y Extranjera, Agencia de Información Mexicana, Agencia Argos, Continental News Service, Agencia Periodística Latino Americana, Oficina de Becerra Acosta, Centro Mexicano de Informaciones Periodísticas "Argos" y Agencia Mexicana de Prensa. A estas agencias formales debemos sumar las distintas iniciativas políticas continentales que actuaron también como medios de comunicación. Creo necesario realizar esta extensa lista para visualizar la amplitud y la complejidad del esfuerzo comunicacional que se desplegó durante la década de 1920. Estas entidades iban desde simples tiendecillas que manipulaban recortes de periódicos, hasta algunas que lograban surcar el océano Atlántico para conectar dos continentes. Todas, sin embargo, mantuvieron relaciones estrechas con el gobierno y compartieron, ya fuera por convicción o por motivos estratégicos, los principales postulados de las autoridades mexicanas.

La campaña propagandística que emprendieron los gobiernos posrevolucionarios tuvo uno de sus pilares, no en determinada agencia, sino en la convergencia de un espacio informativo complejo capaz de difundir desde distintas 
perspectivas informaciones favorables. Si no atendemos esta situación podríamos establecer que la desorganización y la falta de planificación fueron las prácticas comunes. Sin embargo, sin desatender que algo de ello hubo, la estrategia gubernamental fue capaz de utilizar en su propio beneficio un escenario que actuaba bajo las reglas del desorden (Duhau y Giglia, 2008).

\section{LISTA DE REFERENCIAS}

-Agencia Duems (1923). Mexiko: Politik, Wirtschaft, Kultur der Vereinigten Staaten von Mexiko. Berlín: s. e.

-Álvarez, J. T. (2005). Historia y modelos de comunicación en el siglo XX. La Habana: Editorial Pablo de la Torriente.

-Britton, J. A. (1995). Revolution and ideology. Images of the Mexican in the United States. Lexington: The University Press of Kentucky.

-Burkholder, A. (2007). La red de los espejos: una historia del diario Excélsior, 1916-1976. (Tesis doctoral). Instituto de Investigaciones Dr. José María Luis Mora, México.

-Chomsky, N. y Herman, E. (2003). Los guardianes de la libertad. Barcelona: Editorial Crítica.

-Cuthbert, M. (1980). Reaction to international news agencies: 1930 s and 1970 s. Compared. International Communication Gazette, 26, 99-110, Ámsterdam.

-Desbordes, R. (2008). Representing 'informal empire' in the nineteenth century. Media History, 14(2), 121-139, Londres-Nueva York.

-Díaz Vázquez, M. del C. (2008). Intelectuales centroamericanos y el México posrevolucionario, 1920-1930. Latinoamérica. Revista de Estudios Latinoamericanos, 46, 119-139, México.

-Díaz Rangel, E. (1991). La información internacional en América Latina. Caracas: Monte Ávila Editores.
-Duhau, E. y Giglia Á. (2008). Las reglas del desorden. Habitar la metrópoli. México: Universidad Autónoma Metropolitana-Azcapotzalco/Siglo XXI Editores.

-Gardner, M. A. (1967). The Inter American Press Association: Its fight for freedom of the press, 1926-1960. Austin: University of Texas Press.

-González, J. (2001). Frentes culturales: para una comprensión dialógica de las culturas contemporáneas. Estudios sobre las Culturas Contemporáneas, 2(14), 9-45, Colima.

-González Marín, S. (2006). Prensa y poder político. La elección presidencial de 1940 en la prensa mexicana. México: Siglo XXI Editores/Instituto de Investigaciones Bibliográficas-UNAM.

-González Rodríguez, S. (1989). El misterio de Wilfrid Ewart. Nexos. 1 de diciembre de 1989.

-Mañón, D. A. (1931). Espíritu americanista: México, Guatemala, El Salvador, Honduras, Cuba. Santo Domingo: s. e.

-Mañón, D. A. (1929). Exaltación patriótica. Nueva literatura revolucionaria. Conquistando la nacionalidad mexicana. Santo Domingo: Imprenta Montalvo.

-Martín-Barbero, J. (2010). De los medios a las mediaciones. Comunicación, cultura y hegemonía. México: Anthropos/Universidad Autónoma Metropolitana.

-Mattelart, A. (1998). La mundialización de la comunicación. Buenos Aires: Paidós.

-Morales, E. (2001). La diversidad informativa latinoamericana en México. México: UNAM.

-Murphy, D. T. (1997). The heroic Earth. Geopolitical thought in Weimar Germany, 19181933. Kent, Ohio y Londres: The Kent State University Press.

-Múzquiz Blanco, M. (1925). Crónicas, entrevistas y conferencias. México: Tipografía E. Correccional.

-Planas, P. (1986). Los orígenes del APRA. El Joven Haya. Lima: Editores Okura.

-Putnis, P. (2006). How the international news agency business model failed - Reuters in 
Australia, 1877-1895. Media History, 12(1), 117, Londres-Nueva York.

-Rantanen, T. (2006). Foreign dependence and domestic monopoly: The European news cartel and U. S. Associated Presses, 1861-1932. Media History, 12(1), 19-35, Londres- Nueva York.

-Read, D. (1999). The powers of news. The history of Reuters. Oxford: Oxford University Press.

-Robleto, H. (1931). Plus de Révolution au Mexique. L'Amerique Latine. 16 de octubre de 1931.

-Roldán Vera, E. (2009). Los orígenes de la radio educativa en México y Alemania: 1924-1935. Revista Mexicana de Investigación Educativa, 14(40), 13-41, México.

-Secretaría de Relaciones Exteriores (1930). Boletín de la Secretaría de Relaciones Exteriores. México: SRE.

-Serna, A. M. (2010). Periodistas mexicanos: ¿voceros de la nueva Doctrina Monroe? Mexican Studies/Estudios Mexicanos, 26(2), 207237, California.

-Torres, T. (1937). Periodismo. México: Ediciones Botas.

-Velasco Valdés, M. (1955). Historia del periodismo mexicano (apuntes). México: Librería de Manuel Porrúa.

-Yankelevich, P. (1997). Miradas australes. Propaganda, cabildeo y proyección de la revolución mexicana en el Rí de la Plata. 1910-1930. México: Secretaría de Relaciones Exteriores/Instituto Nacional de Estudios Históricos de la Revolución Mexicana.

\section{OTRAS FUENTES}

Archivos

AGN Archivo General de la Nación.

AHMRReE Archivo Histórico del Ministerio de Relaciones Exteriores, Chile.

AHSRE Archivo Histórico de la Secretaría de Relaciones Exteriores, México.

FAPECFT Fideicomiso Archivo Plutarco Elías Calles y Fernando Torreblanca.

FRUNAM Fondo Reservado UNAM.

NAW The National Archives of Washington.

\section{Periódicos}

-El imparcial, 1923, Guatemala.

-El Libro y El Pueblo, 1923-1924, México.

-El Universal, 1926, México.

-La Libertad, 1927, Madrid.

-Mexican Daily News, 1930-1931, México.

\section{()(1)}

